\title{
Análisis de la imagen de la mujer transmitida en las actuales carátulas de videojuegos
}

institucionales.us.es/ambitos/

\section{Guillermo Paredes Otero \\ Universidad de Sevilla \\ gparedes@us.es}

English Version: Analysis of the image of the women transmitted in the current videogames covers

El presente artículo muestra los resultados obtenidos tras la investigación efectuada en el campo de los estereotipos de género y los videojuegos. El objetivo principal ha sido conocer, mediante la aplicación de un análisis de contenido, si los modelos femeninos que se transmiten actualmente en las carátulas de los videojuegos mantienen elementos de carácter sexista.

Palabras clave: videojuegos, estereotipos, imagen, carátulas.

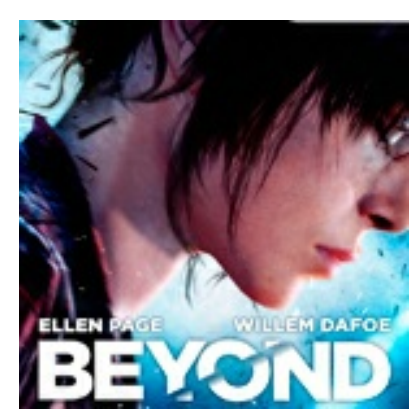

Abstract: The present article shows the results obtained after the research carried out in the field of gender stereotypes and videogames. The main objective has been knowing, by means of the application of a content analysis, if the female models are being currently transmitted in the covers of videogames maintain elements of a sexist character.

Keywords: videogames, stereotype, image, cover.

\section{INTRODUCCIÓN}

El videojuego es en suelo español una de las industrias que mayor proyección tiene. Según el informe [1] realizado por la Asociación Española de los Videojuegos (AEVI), este sector facturó en 2016 más de 1.163 millones de euros, casi el doble de la cantidad generada por el cine (601 millones) y muy superior a la industria discográfica (163,7 millones), siendo el sector de entretenimiento audiovisual más lucrativo de nuestro país. En cuanto al comportamiento del videojugador, 15 millones de personas dedicaron una media de seis horas semanales al uso de videojuegos. Actividad que registra una igualdad de géneros en cuanto a perfil de usuario se refiere siendo el $56 \%$ hombres y el $44 \%$ mujeres y con preferencia para las franjas de edad de entre los 6 y los 34 años.

Más allá de ser considerado como un simple producto, el videojuego es una potente herramienta socializadora, de hecho, es de las primeras que el sujeto se va a encontrar en su vida teniendo en cuenta la edad a la que se empieza a consumir este entretenimiento, y transmisores de valores. Sin embargo, en cuanto a investigaciones sobre estereotipos y roles se ha detectado un vacío científico en los últimos años que se pretende paliar con la presente investigación.

\section{ESTADO DE LA CUESTIÓN. LA INVESTIGACIÓN EN VIDEOJUEGOS Y GÉNERO}


La investigación en el campo de los videojuegos es frecuente que se centre en analizar la importancia que tiene este producto audiovisual en el ámbito educativo y su aplicación en las aulas. Sin embargo los estudios de género relacionados con los videojuegos son escasos y se basan en unas ramas de investigación que a continuación se proceden a identificar.

Por un lado autores como Gil, A y Vall-Llovera, M. (2009) se han dedicado a hallar las diferencias de género a la hora de utilizar los videojuegos debido a la desigualdad existente en el uso y acceso a las nuevas tecnologías dependiendo de si es hombre o mujer quien utiliza el soporte y llegando a la conclusión de que "el nivel de acceso de las chicas a los videojuegos sigue siendo muy bajo respecto a los chicos, lo cual dificulta el que las chicas adopten prácticas tecnológicas que redundarían en un incremento de su interés y dominio de las nuevas tecnologías"(p.14).

No obstante, este argumento no casa con el último informe emitido por la AEVI, mencionado en el epígrafe anterior, donde se muestra que casi la mitad de consumidores españoles de videojuegos son mujeres. La diferencia existente entre ambos textos de siete años es una prueba de cómo evoluciona la sociedad y el cambio en el perfil del consumidor de videojuegos.

La segunda línea de trabajo se ocupa de analizar los roles y estereotipos sexistas en los videojuegos, es decir, el tratamiento de la figura femenina en los videojuegos, especialmente de los roles y los estereotipos, y parte de la base de que los videojuegos reproducen estereotipos de género de forma masiva, dando lugar al reforzamiento de la discriminación en razón del sexo.

Destaca en este campo el análisis de carátulas de videojuegos para Nintendo realizado por Eugene F. Provenzo (1991, visto en Rodríguez R., 2016, p.201) y extraía la conclusión de que "existía una evidente subordinación de los personajes femeninos en los videojuegos". Años más tarde encontramos la investigación realizada por Enrique Javier Díez Gutiérrez (2004) cuya conclusión fue que los videojuegos "tienden a reproducir estereotipos sexuales contrarios a los valores que educativa y socialmente hemos establecido como principios básicos en nuestra sociedad"(p.329). Por su parte Rodríguez, R. (2016, p. 201) describe como "las mujeres suelen encarnar personajes pasivos o simplemente decorativos e hipersexualizados; mientras que los personajes masculinos se caracterizan por su fuerza, su papel protagonista y dominante, su capacidad resolutiva, etc".

Finalmente, existe una tercera vía de investigación como destacan Feliú y Heredia (2009) referida a los videojuegos como laboratorio de identidades.

En vista de las tres líneas de investigación descritas, el presente trabajo se ha enmarcado en la segunda ya que busca analizar si, a través de las carátulas de los videojuegos, se emiten contenidos sexistas y una visión estereotipada de la figura de la mujer. De esta forma no tiene cabida en este trabajo cómo se accede a estos videojuegos en función del género ni cómo se construye la identidad, para ello habría que analizar la interacción con el producto en su conjunto.

En materia de análisis de carátulas de videojuegos y la imagen que representan los personajes que aparecen, aparte de la investigación de Provenzo en 1991, existen trabajos previos a esta investigación como es el caso de las ya citadas Bueno y García (2012), en el que analizan los estereotipos de género que ofrecen las portadas de la colección de 
videojuegos Imagina Ser y Díez Gutiérrez (2004) donde las pautas de conducta que transmiten los videojuegos y sus efectos en la población infantil son su objeto de estudio. Sin embargo, el presente estudio ha tenido dos puntos que lo avalan y diferenciadores. Por un lado, las investigadoras Bueno y García se centran efectivamente en analizar carátulas, pero son las imágenes de una colección específica de videojuegos con una línea y destinados a un público concreto. En este caso, la investigación que se ha realizado abarca los videojuegos en general, sin importar factores como la edad, la compañía que los producen y el género del producto (juegos deportivos, de acción, de aventuras, shooter, etc).

Por otro lado Díez Gutiérrez aunque analizó videojuegos de diferente tipología, su estudio se realizó hace catorce años por lo que ha sido interesante comprobar si las conclusiones que sacó en su momento se mantenían en la actualidad. Además es necesario tener en cuenta que su investigación se centró en el videojuego en sí, no en las carátulas como es nuestro caso.

\section{METODOLOGÍA}

La hipótesis principal de la que ha partido esta investigación es que se ha producido un cambio en los estereotipos de género a la hora de representar a la mujer en las carátulas de videojuegos dejándose a un lado los modelos tradicionales sexistas.

Para verificar o refutar esta hipótesis planteada, el objetivo principal de este trabajo ha sido investigar los estereotipos de género que transmiten las carátulas de videojuegos en la actualidad. Algunos investigadores han realizado críticas hacia los estudios que solamente analizan portadas (Jansz, J. y Martis R.G., 2007), sin embargo se ha procedido a realizar este estudio al coincidir con las argumentaciones que expone Provenzo (1991, citado en Bueno, T. y García, N. 2012), en este sentido ya que: "representan una unidad de análisis fácilmente cuantificable, suponen un intento de resumir visualmente el contenido del juego y aparecen conjuntamente con anuncios promocionales en los lugares de venta sintetizando el juego y su propuesta"(p.15).

Esta investigación por lo tanto se ha desarrollado en tres fases. En primer lugar ha sido necesaria una revisión teórica de estudios previos sobre la representación de la mujer en los videojuegos, tanto en el apartado jugable, es decir, el aspecto en el que se interactúa con el personaje, como en las carátulas con las que se pone a la venta el producto. En esta fase también se ha incluido la selección de la muestra a analizar cuyos requisitos se explicarán en párrafos posteriores.

Una vez obtenidas las imágenes se ha procedido a su visualización con la finalidad de realizar un análisis de contenido atendiendo a unas categorías concretas. Posteriormente se ha procedido a la interpretación de los datos y el establecimiento de relaciones entre características comunes entre las imágenes seleccionadas. Dicho de otra forma y atendiendo a Casetti y Di Chio (1991), primero se ha segmentado del objeto (en este caso cada una de las carátulas) en distintas partes o elementos. "Se trata de individuar en una especie de continuo los fragmentos que lo componen, y de reconocer como algo lineal la existencia de una serie de confines" (p.34).

Por último, una vez obtenidas unas conclusiones parciales en función de las categorías tenidas en cuenta de manera independiente, la tercera fase ha consistido en la enunciación de las conclusiones finales y generales para confirmar o refutar la hipótesis formulada. "De 
nada sirve establecer relaciones si éstas no se reconducen hacia una visión unitaria del objeto que establezca los sentidos, a través de una representación sintética, de sus principios de construcción y de funcionamiento"(Ibídem, p.35).

El método seleccionado para esta investigación ha sido el análisis de contenido aplicado a las figuras femeninas que aparecen como reclamo en las portadas de los videojuegos, con el fin de detectar los estereotipos de género presentes en los mensajes publicitarios. Este método de trabajo, no está exento de detractores tal y como indican Arroyo y Sábada (2012):

"Las principales críticas a esta modalidad de análisis se han centrado en su incapacidad para captar los aspectos latentes de un proceso de comunicación, en este caso de un documento visual, que, generalmente es caracterizado como fuertemente connotativo. Sin embargo, estos aspectos latentes y connotados son, en muchas ocasiones, los más significativos de cara a la atribución de sentido"(p. 235).

A pesar de las críticas, el análisis de contenido se considera idóneo para esta investigación ya que permite determinar la frecuencia con que determinados patrones aparecen en los documentos visuales que componen la muestra. Por otro lado, como se indica en el informe UNESCO 'Imagen, papel y condición de la mujer en los medios de comunicación social' (Ceulemans, M. y Fauconnier, G., 1981), el análisis de contenido y el estudio de la actitud y opinión son dos índices de comprobación válidos para estudiar en qué medida las mujeres aparecen estereotipadas en la publicidad(Ibídem, p.10).

La muestra de imágenes que han compuesto el análisis iconográfico ha estado formada por 20 carátulas de videojuegos para consolas de sobremesa y portátiles que cumplen con los siguientes requisitos: la carátula debía corresponder a un juego lanzado en los últimos seis años, es decir, entre 2012 y 2017, juegos que aún se están comercializando en España y son propensos a llegar al consumidor, no solamente el producto sino también el estereotipo de género que aparece en portada. Además, al menos debía aparecer un personaje femenino en primer o segundo plano.

De esta forma las carátulas analizadas corresponden a los juegos: Assassin's Creed Syndicate (2015), Assassin's Creed III: Liberation (2014), Beyond: Two Souls (2013), Bioshock: Infinite (2013), Destiny 2 (2017), FIFA 16 (2015), Horizon: Zero Dawn (2017), Life is Strange (2015), Lightning Returns: Final Fantasy XIII (2014), Mirror's Edge Cathalist (2016), New Style Boutique (2012), Overwatch (2016), Rise of the Tomb Raider (2015), Remember Me (2013), Helblade: Senua's Sacrifice (2017), Syberia 3 (2017), The Last of Us (2013), Tomb Raider (2013), Uncharted: The Lost Legacy (2017) y White Day: A Labyrinth named school (2017).

\section{CONCLUSIONES DEL ANÁLISIS DE CONTENIDO}

En este apartado del la investigación se exponen las conclusiones alcanzadas tras el trabajo empírico realizado. De esta forma las relaciones obtenidas entre los elementos de las carátulas de los videojuegos tras el análisis de dichas imágenes individualmente se han catalogado y expuesto a lo largo de ocho categorías. Para demostrar los argumentos se han citado los juegos que han servido para realizar la afirmación, cuyas carátulas pueden encontrarse en el apartado de Anexos.

\subsection{Rol ocupacional}


La forma de presentar a la mujer en la publicidad respecto al rol con las que se las representa suele ser a través de un menor status social, desempeñando funciones dependientes y tradicionales como amas de casa, cuidadoras de niños o pertenecientes al ámbito del espectáculo como el cine y la música interpretando el papel de actriz o cantante, es decir, como mero objeto para el consumo pero no como figura de autoridad. Igualmente, en la temática de belleza y bienestar la protagonista suele ser una figura femenina que consume productos de belleza y saludables ya que se relaciona a este género con la idea de preocupación por la salud y su físico. Por lo tanto, existen unos estereotipos de género en relación a la mujer claramente definidos. Sin embargo, atendiendo a la muestra seleccionada, nos encontramos con conclusiones muy diferentes a las que reflejan otro tipo de elementos propagandísticos como los anuncios de televisión o prensa en papel (revistas) y digital (banners) ya que los carteles de videojuegos muestran un tipo de mujer diferente en todos los casos.

Sin embargo, analizando las carátulas se presenta a la mujer realizando profesiones que requieren una mayor actividad física tales como cazadoras (Horizon: Zero Dawn y Tomb Raider) o exploradoras como en el caso de Rise of the Tomb Raider. Especial atención a la carátula del videojuego FIFA 16. No es casualidad que una mujer aparezca con la misma pose que Leo Messi, considerado como uno de los mejores jugadores del fútbol del mundo. La intencionalidad es la de lanzar el mensaje, por un lado de que no importa el género, si se tiene talento se puede jugar junto a las estrellas del fútbol, y por otro de atraer al sector femenino a consumir un tipo de juego que claramente tiene como principal consumidor un público masculino.

\subsection{Presentación de la figura principal}

En esta variable se establece si la figura de la mujer aparece acompañada por personajes masculinos o si lo hacen en solitario. Atendiendo a la muestra seleccionada se extrae que en un $25 \%$ de las carátulas, la figura femenina aparece acompañada por personajes masculinos, mientras que en un $75 \%$ son mostradas en solitario. De esta forma se puede afirmar que las protagonistas de videojuegos adoptan un rol autónomo a pesar del alto porcentaje en el que están acompañadas en las carátulas con figuras masculinas.

\subsection{Posición respecto a la figura masculina}

Esta categoría podría considerarse subcategoría de la anterior. Consiste en analizar si los personajes femeninos ocupan un papel protagonista en las carátulas en las que aparecen acompañadas de hombres. En un $80 \%$ de las carátulas en las que aparecen hombres y mujeres, los iconos femeninos aparecen en un segundo plano, teniendo todo el protagonismo el hombre. A destacar la carátula Assassin's Creed Syndicate en la que, de los seis personajes que aparecen, solo dos son mujeres: una aparece en un lateral y cortada mientras que la segunda aparece en el fondo de la imagen. El único caso de la muestra en la que la mujer está por delante del hombre es en la portada de The Last of Us. Respecto a las carátulas en las que solamente hay personajes femeninos, éstos ocupan la parte central de la carátula un $86,6 \%$ de las veces. El 13,4\% restante corresponde a las veces en las que la mujer simplemente ocupa un lateral para darle mayor importancia al título del videojuego.

\subsection{Vestimenta}


En este apartado se expone la forma en que el personaje femenino aparece vestido en las carátulas. Esta categoría está dividida en varios apartados en función del nivel de exposición del cuerpo de la mujer. De esta forma puede darse el caso de desnudos parciales leves (escote, espalda, hombros y piernas hasta la rodilla), desnudo parcial severo (escotes y espaldas más pronunciadas, dejando entrever los pechos y piernas por encima de la mitad del muslo), desnudo total o ausencia de exhibición del cuerpo más allá de la cara y las manos. Respecto a la muestra analizada, aunque se asocia la mujer al desnudo y a la exhibición de su cuerpo en cuanto se refiere al sector de los videojuegos, esto no ocurre debido a que en un $90 \%$ de las imágenes la mujer no exhibe su cuerpo a excepción de brazos, manos y cara. El 10\% restante corresponde a desnudo parcial severo debido a que las mujeres de dichas carátulas mostraban casi la totalidad de sus piernas al usar vestidos y minifalda por encima de la rodilla (New Style Boutique y White Day: A Labyrinth named school).

\subsection{Belleza física}

En esta categoría se procede a analizar si la belleza física está presente en la representación de la mujer en las carátulas de la muestra seleccionada. Analizando los elementos con los que se relaciona el ideal de belleza física -juventud, delgadez y perfección corporal- (Bernard, E., Zeynep, A. y Fernández, C., 2012) hay que decir que en todos los casos se cumple esta máxima sin la necesidad de hipersexualizar a la figura de la mujer. Todas las figuras femeninas son jóvenes (esto se explicará más detenidamente en la siguiente variable). Teniendo en cuenta la mirada, se refleja intensidad e incluso diversión, esto último puede verse en los casos de New Style Boutique u Overwatch Origins. Quitando las carátulas en las que las mujeres salen con los ojos cerrados (Beyond: Two Souls y Syberia 3), un $40 \%$ de la muestra está compuesta por figuras femeninas con ojos azules o claros (Lightning Returns: Final Fantasy XIII o Hellblade: Senua's Sacrifice), colores asociados a la dulzura. Por lo tanto se extrae como conclusión que un alto porcentaje de las mujeres se alejan del estereotipo de "princesa" con mirada tranquila y pelo largo (véase caso de Life is Strange y Remember Me) sin que ambas protagonistas, con pelo corto, pierdan belleza física. Respecto a la complexión, todas las imágenes muestran una figura delgada sin que haya excepción.

\subsection{Edad y raza}

Con esta variable se pretende analizarla edad en la que aparece representada la figura femenina en las carátulas. Si tenemos en cuenta que la adolescencia comprende desde los 15 hasta los 19 años; los adultos jóvenes, desde los 20 a los 39; los adultos medios, desde los 40 a los 49 años; y los adultos maduros, a partir de los 50 años (Martín, J.F., 2005), el 85\% de los personajes femeninos que aparecen en las carátulas de la muestra seleccionada son jóvenes que no llegan a la edad adulta media. El 15\% restante corresponde a figuras adolescentes. En ningún caso hay representados iconos maduros.

Respecto a la raza, la estadística en este aspecto es contundente con un $80 \%$ de mujeres occidentales y blancas. Por su parte, un $15 \%$ de la muestra analizada muestra a figuras femeninas de color (Assassin's Creed III: Liberation, Remember Me, Uncharted: The Lost Legacy) y sólo un $5 \%$ de asiáticas (White Day: A Labyrinth named school).

\subsection{Violencia}


La violencia es uno de los aspectos más estudiados en los videojuegos, sobre todo a la incitación a la agresividad tras el uso de este tipo de entretenimiento y a aceptar la violencia con mayor facilidad. Por lo tanto, esta variable es imprescindible que esté en este análisis. La idea es comprobar si se cumple la premisa de, mientras al hombre se le relaciona con la violencia, mostrar a la mujer en una actitud tranquila, pasiva y desprotegida siendo necesaria la presencia de un icono masculino que la proteja.

Para determinar la presencia de violencia en las carátulas se establece el requisito de que para considerar una actitud violenta por parte de la mujer, ésta debe llevar algún tipo de arma o estar en actitud de lucha. Teniendo este requisito en cuenta, de la muestra realizada, en un $55 \%$ de las carátulas vistas la figura femenina está implicada de alguna forma en situaciones violentas, de esta forma puede afirmarse que la violencia ya no es un factor en los videojuegos relacionado exclusivamente con el hombre.

Teniendo en cuenta exclusivamente las carátulas con elementos violentos, en un $90,9 \%$ de dicha selección la mujer, independientemente de la actitud del hombre, lleva un arma como es el caso de cuchillas (Assassin's Creed Syndicate o Assassin's Creed III: Liberation), arcos (Horizon: Zero Dawn, Rise of the Tomb Raider o Tomb Raider) y armas de fuego (Destiny 2, Overwatch o The Last of Us).

Por otro lado, la única carátula con elemento violento en presencia del hombre y en ausencia de la mujer es la de Bioshock: Infinite donde la mujer además de estar en un segundo plano ofrece la sensación de desvalida y necesitada de protección masculina.

Solamente en un $10 \%$ de la muestra escogida el hombre y la mujer usan ambos elementos armamentísticos. Son dos imágenes con una simbología muy diferente. En una de las carátulas (Destiny 2), las figuras masculinas portan las armas más grandes y están más cerca de entrar en combate, quedando la mujer más atrasada y con un arma más pequeña o lo que es lo mismo: resaltar la valentía del hombre frente a la cautela de la mujer. La segunda carátula a destacar es la de The Last of Us donde ocurre lo contrario: el hombre lleva el arma más pequeña y está retrasado respecto a la figura femenina, una niña, con un arma más grande 2 . De esta forma se extrae la conclusión en esta variable de que la mujer ya no ocupa un rol de indefensión y necesidad de un hombre que la proteja sino que es capaz de valerse y defenderse por sí misma. Otro posible punto de vista sería el afirmar que en algunas carátulas los personajes femeninos asumen características encuadradras al estereotipo del género masculino como la fuerza y la violencia, es decir, se masculiniza a la mujer.

\subsection{Sexualidad}

Al margen de la vestimenta usada por los personajes femeninos de la muestra analizada y la cantidad de cuerpo que se expone, el último parámetro que se tiene en cuenta es la presencia de sexualidad en las imágenes. La figura de la mujer representada en los videojuegos siempre se ha caracterizado por una hipersexualidad a la hora de representarla, es decir, figura de reloj de arena, senos de tamaño exagerado y posturas sensuales para llamar la atención del público, el cual era predominantemente masculino. En palabras de Díez Gutiérrez "la sexualidad femenina se remarca especialmente por los vestidos semitransparentes e insinuantes que llevan las mujeres" (2004, p.339). No obstante, la muestra indica un cambio en este aspecto habiendo ejemplos en los que el personaje femenino va completamente tapada, como quedó reflejado en la categoría de Vestimenta, o usando prendas de vestir cotidianas como camisetas o abrigos, sin presentar ningún elemento 
diferenciador y acorde al rol que representan.

De hecho, en algunos casos hay prácticas totalmente contrarias. A destacar como en dos carátulas en las que las protagonistas usan vestimenta que realza el tamaño de los pechos, se ha colocado el título del juego justo en la zona del busto de la mujer (Assassin's Creed III: Liberation y (Lightning Returns: Final Fantasy XIII, algo que contradice la tendencia expuesta en el párrafo anterior. De existir algún tipo de intencionalidad sexual sería en el caso de la carátula de Mirror's Edge Cathalist donde la protagonista está con ambas piernas extendidas en posición horizontal y Remember Me donde la protagonista lleva unos vaqueros que resalta sus glúteos.

\section{CONCLUSIONES}

A raíz del análisis realizado se ha comprobado que las portadas de los videojuegos han cambiado la forma de presentar a la mujer, muy alejada de los estereotipos clásicos que se ofrecía en este entretenimiento. Aunque se mantienen factores como el uso de personajes de raza blanca, jóvenes y delgadas, la tendencia actual es ubicar a la mujer en el centro de la carátula, representando roles asociados hasta la fecha al hombre y ejerciendo algún tipo de violencia, mientras al mismo tiempo usa una vestimenta alejada del erotismo y la desnudez del cuerpo. Por lo tanto se verifica la hipótesis inicial en la que se exponía que las carátulas con las que se venden los videojuegos utilizan estereotipos de género diferentes a los tradicionales modelos de representación femenina que tenían una alta carga de hipersexualización y un rol de mujer como objeto erótico. Sin embargo, es necesario señalar que en muchos casos se mantiene la tendencia a masculinizar a la mujer a la hora de atribuirles estereotipos masculinos clásicos como la violencia. También ha sido constatable la ausencia de la sumisión reflejada por Provenzo en su estudio hasta el punto de existir casos de títulos protagonizados solamente por mujeres.

\section{FUTURAS LÍNEAS DE INVESTIGACIÓN}

Cada una de las categorías en las que se ha dividido el análisis de contenido de las carátulas pueden ser por sí mismas una investigación propia, con especial atención a las dedicadas a 'Posición respecto a la figura masculina', 'Violencia' y 'Sexualidad' al representar los aspectos más polémicos con los que se relaciona, no ya a la mujer sino, a todo el sector de los videojuegos.

Durante la realización de esta investigación han surgido otras ideas que podrían ser tema de estudio. Por un lado, sería interesante comprobar si la imagen que muestran los personajes femeninos representados en las carátulas que componen la muestra analizada realmente se corresponde con aquella que luego se refleja dentro del videojuego.

De la misma forma también podría analizarse qué perfil de mujer, no solamente en las carátulas sino el personaje con el que el jugador interactúa cuando coge el mando, se presenta según la desarrolladora que crea el producto. La feminidad que enseña empresas europeas como Ubisoft no es la misma que puedan diseñar homólogas asiáticas como Nintendo o Capcom ya que hay que atender a otros factores como son el ámbito cultural de cada región así como el tipo de consumidor al que se destina el producto. 
Los videojuegos como tal son un género de entretenimiento relativamente reciente si se comparan con otros sectores como la música o la literatura, apenas tienen cuarenta años de existencia. Esto, sumado al hecho de ser una industria que está en continua evolución tecnológica y que se está introduciendo en ramas más allá del entretenimiento, como por ejemplo en la educación con la gamificación y los serious games, hace que exista un extenso campo fértil para investigar este tipo de ocio audiovisual.

\section{ANEXO}

\section{Ver documento PDF}

\section{REFERENCIAS}

Asociación Española de Videojuegos (AEVI) (2016). Anuario de la Industria del Videojuego (2016), . [en línea]. [Acceso el 4 de enero de 2018]. <http://bit.ly/2CuH58G>

Arroyo, M. y Sábada, I. (2012): Metodología de la investigación social. Técnicas innovadoras y sus aplicaciones, Madrid: Editorial Síntesis.

Bernard, E., Zeynep, A. y Fernández, C. (2012), Publicidad de la industria de la belleza y mercado de trabajo: la belleza asociada al éxito profesional. Investigación y género, inseparables en el presente y en el futuro: IV Congreso Universitario Nacional Investigación y Género, Universidad de Sevilla. [en línea]. [Acceso el 3 de enero de 2018]. $<$ http://bit.ly/2B0O0Vm>

- Bueno, T. y García, N. (2012): Los roles tradicionales femeninos presentes en las carátulas de los videojuegos infantiles. Revista Creatividad y Sociedad N XIX. [Acceso el 27 de diciembre de 2017].

<http://www.creatividadysociedad.com/articulos/19/Los\%20roles\%20tradicionales\%20femeninos.pdf>

Casetti, F. y Di Chio, F. (1991): Como analizar un film, Barcelona, Paidós Ibérica.

Ceulemans, M. y Fauconnier, G. (1981): Imagen, papel y condición de la mujer en los medios de comunicación, UNESCO. [en línea]. [Acceso el 4 de enero de 2018].

$<$ http://bit.ly/2AXY1CQ>

Díez, E.J., (2004): La diferencia sexual en el análisis de los videojuegos, Instituto de la Mujer y CIDE [en línea]. [Acceso el 4 de enero de 2018].

<https://sede.educacion.gob.es/publiventa/d/13091/19/0>

Feliu, J. y Heredia, J. (2012): Líneas de investigación en videojuegos y género: presente de desigualdad ¿futuro de?, Meddia, cultura i comunicació: Actas del IV Congreso Online del Observatorio para la Cibersociedad [en línea]. [Acceso el 3 de enero de 2018].

$<$ https://dialnet.unirioja.es/servlet/articulo?codigo=3336570>

Gil, A y Vall-Llovera, M. (2009): Género, TIC y videojuegos, Barcelona, Editorial OUC.

Jansz, J. y Martis, R.G. (2007) The Lara Phenomenon: Powerful Female Characters in Video Games, Sex Roles, vol. 56, No 3-4 [en línea], pp. 141-148. [Acceso el 3 de enero de 2018]. <https://link.springer.com/article/10.1007/s11199-006-9158-0>

Martín, J.F., (2005): Los factores definitorios de los grandes grupos de edad de la población: tipos, subgrupos y umbrales, Scripta Nova. Revista Electrónica de Geografía y Ciencias 
Sociales Vol. IX, núm. 190 [en línea]. [Acceso el 3 de enero de 2018].

<http://www.ub.edu/geocrit/sn/sn-190.htm>

Provenzo, E.F. (1991): Video Kids: making sense of Nintendo, Harvard University Press, Cambridge.

Rodríguez, R. (2016): Videojuegos. La explosión digital que está cambiando el mundo, Sevilla, España, Héroes de papel.

[1] 'Anuario de la Industria del Videojuego' para el año 2016 realizado por la Asociación Española de Videojuegos (AEVI)

[2] Para entender completamente el significado de esta carátula hay que haber jugado a este videojuego. The Last of Us tiene lugar en Estados Unidos, la carátula es una clara alusión a la libertad que existe en dicha zona de acceder a un arma debido a la falta de control y regulación.

\section{BREVE SEMBLANZA DEL AUTOR:}

Guillermo Paredes Otero es Graduado Superior en Ciencias de la Comunicación, especialidad Periodismo por la Universidad de CEADE. Tiene Máster en Periodismo Digital por la Universidad de Alcalá de Henares y Máster en Periodismo Deportivo por la Escuela CES de Imagen y Sonido. Actualmente cursa el Máster en Comunicación y Cultura de la Universidad de Sevilla. Es Personal Científico en prácticas del Grupo de Investigación en Estructura, Historia y Contenidos de la Comunicación (GREHCCO), con un contrato de fondos FEDER.

- Recibido: 06/03/2018

- Aceptado: 09/03/2018

Ámbitos. Revista Internacional de Comunicación, n.40, edición de primavera, 2018. 